\title{
Constipation and paradoxical puborectalis contraction in anismus and Parkinson's disease: a dystonic phenomenon?
}

\author{
S E MATHERS,* P A KEMPSTER, $\dagger$ M SWASH,* A J LEES $\dagger$ \\ From the Sir Alan Parks Physiology Laboratory, St Mark's Hospital ${ }^{*}$ and Department of Neurology, \\ Middlesex Hospital, $\uparrow$ London, UK
}

SUMMARY Anismus, or constipation due to functional obstruction at the pelvic outlet by paradoxical contraction of the striated sphincter muscles during defaecation straining, is described in ten constipated patients and four patients with Parkinson's disease and constipation. The dysfunctional pattern of muscle recruitment resembled that characteristic of dystonia elsewhere in the body and was indistinguishable in patients with idiopathic anismus and those with extrapyramidal motor disturbance due to Parkinson's disease. These findings suggest that anismus may be a focal dystonic phenomenon.

Among patients with chronic constipation, a group can be identified in which disturbed relaxation of the striated pelvic floor and anal sphincter musculature leads to functional obstruction of defaecation at the pelvic outlet. This phenomenon has been termed anismus ${ }^{1}$ or spastic pelvic floor syndrome ${ }^{2}$ but its underlying pathophysiological basis is not known. The term anismus was derived by analogy with the involuntary contraction of the pelvic floor muscles said to occur in vaginismus. ${ }^{1}$ Patients with anismus are usually female and present in childhood or early adult life. There is seldom evidence of associated neurological or gastroenterological disease. Electrophysiological assessment shows paradoxical puborectalis and external anal sphincter contraction during attempted defaecation. There is evidence that chronic straining at stool during many years may lead to stretch induced damage to the pudendal innervation of the external anal sphincter muscles. ${ }^{3}$

Inappropriate or paradoxical patterns of skeletal muscle activation, often precipitated or worsened during the execution of voluntary motor tasks, are typical of dystonia. The adult-onset focal and segmental dystonias such as blepharospasm, oromandibular

Address for reprint requests: Dr M Swash, Sir Alan Parks Physiology Laboratory, St Mark's Hospital, City Road, London ECIV 2PS, UK.

Received 10 May 1988 and in revised form 24 July 1988. Accepted 28 July 1988 dystonia, writer's cramp, spasmodic dysphonia and spasmodic torticollis usually present as isolated motor disturbances and are seldom associated with other demonstrable neurological abnormalities. ${ }^{4}$ They are often influenced by environmental or psychological factors. That these disorders have an organic aetiology, possibly on the basis of disturbance in the extrapyramidal motor system, is suggested by two characteristics. Firstly, similar movement disorders are sometimes seen in association with neurological diseases affecting the basal ganglia such as Parkinson's disease, where they may be presenting features. ${ }^{5-7}$ Secondly, electrophysiological evaluation reveals a consistent pattern of disturbed muscle activation. ${ }^{89}$ These electrophysiological abnormalities include: (1) excessive recruitment of muscle groups during voluntary movement which affects both synergist and antagonist muscles, (2) impairment of the normal reciprocal inhibition of antagonist muscles during voluntary movement, (3) abnormal muscle activation, if present at rest, is increased by attempted movement or may only be seen during movement. In the case of writer's cramp, it is confined to a specific motor task.

We propose that anismus-type constipation is due to a focal dystonia of the pelvic floor muscles. To investigate this hypothesis, the pattern of striated sphincter muscle activation during simulated defaecation straining was studied electrophysiologically in patients with idiopathic anismus and also in patients with Parkinson's disease with and without constipation. 


\section{Patients}

Studies were performed in the Sir Alan Parks Physiology Unit at St Mark's Hospital, London. The pattern of voluntary activation of sphincter and related muscles was assessed in three groups of patients.

\section{(1) Idiopathic (anismus-type) obstructive defaecation}

Ten patients (one male, nine female), aged from 24 to 72 years (mean $\mathbf{4 0}$ years) were studied. Their symptoms had begun in adult life, without obvious precipitating cause and had become intractable. Duration of symptoms ranged from 2 years to 30 years. Five of the nine female patients were nulliparous. One female patient had undergone craniotomy for treatment of trigeminal neuralgia, but otherwise these individuals had no concomitant neurological disease.

All patients described prolonged straining at stool despite an urge to defaecate, some having to resort to anal digitation to aid evacuation of stool. A feeling of incomplete rectal emptying was common.

All had been assessed clinically by their referring surgeon or gastroenterologist. Sigmoidoscopy was normal in all patients except two who had evidence of anterior rectal mucosal prolapse, a condition associated with chronic straining. Two had normal barium enema examinations; the others had undergone defaecating proctography. All but one were abnormal, showing varying degrees of impaired anal canal opening and incomplete rectal evacuation of barium paste. In three cases, there was no emptying at all.

\section{(2) Parkinson's disease}

Six patients with Parkinson's disease were studied (four male and two female). Ages ranged between 39 and 64 years (mean 56.3 years). Four patients complained of constipation. In two of these patients, constipation had occurred for the first time in life several years after the onset of motor symptoms. Another patient had simultaneous onset of constipation and Parkinson's disease. In the fourth patient, constipation had been present in childhood and again during pregnancy but subsequently resolved and recurred one to two years prior to the onset of extrapyramidal motor symptoms at the age of 35 years. However, constipation was abolished in this case when motor function was improved by intermittent subcutaneous injections of the dopamine receptor agonist apomorphine. ${ }^{10}$

Disturbance of striated anal sphincter function was confirmed in all constipated Parkinsonian patients by defaecating proctography after withholding of anti-parkinsonian medication. All had paradoxical contraction of the puborectalis muscle and three were unable to evacuate barium paste owing to impaired relaxation of the anal sphincter muscles.

\section{(3) Control subjects}

Six patients with constipation who did not show abnormal sphincter muscle contraction during straining acted as control subjects. The causes of constipation in this group were: slow intestinal transit (one), rectocoele (one) and descending perineum syndrome (four).

\section{Methods}

Electromyographic (EMG) activity was recorded from four muscles: puborectalis, external anal sphincter, external oblique abdominis and gluteus maximus. With the patient lying in the flexed left lateral position, a concentric needle electrode was placed percutaneously in the puborectalis muscle from a point $1 \mathrm{~cm}$ posterior to the anus directing the point of the needle $45^{\circ}$ anteriorly. Another needle electrode was inserted into the external anal sphincter muscle through the skin $1 \mathrm{~cm}$ lateral to the anal margin. Silver chloride adhesive surface electrodes were placed on the skin overlying the external oblique and gluteus maximus muscles. Ground electrodes were attached to the upper thigh. Needle EMG recordings were made on a Dantec Neuromatic 2000 and surface EMG simultaneously recorded on a Medelec MS-6 apparatus. A latex balloon attached to a soft rubber catheter was placed in the rectum and filled with $50 \mathrm{ml}$ of water to simulate a faecal bolus. Simultaneous recordings of EMG activity in all four muscles were made with the patient at rest, during voluntary sphincter contraction, straining to attempt to expel the rectal balloon, and coughing.

\section{Results}

A command to contract voluntarily the external anal sphincter muscle (EAS) or to cough resulted in increased EMG activity in the puborectalis (PR) and EAS muscles in all patients. The Parkinsonian group were, as expected, slower to initiate voluntary actions. Most patients recruited abdominal and gluteal muscles during sphincter muscle squeezing and the pattern of muscle activation did not differ between the three groups of patients.

During simulated straining at stool, all patients with idiopathic anismus-type constipation and the four Parkinsonian patients with constipation showed a synchronous paradoxical increase in EMG activity in both PR and EAS muscles. Gluteal muscle recruitment during straining was seen in six out of ten of the anismus group and was weakly present in a further three. Gluteal recruitment was present in two of the constipated Parkinsonian patients. No paradoxical sphincter muscle contraction or gluteal muscle recruitment was seen in the two Parkinsonian patients without constipation or in the control patients. Typical patterns of EMG activity in the three patient groups are illustrated in figs 1-3.

The response to dopamine receptor agonist administration was objectively studied in the Parkinsonian patient who described marked subjective improvement in constipation when treated with self administered subcutaneous apomorphine. Following apomorphine injection, paradoxical striated sphincter muscle contraction could still be detected electromyographically during defaecation straining. However, defaecating proctography showed reduction in paradoxical puborectalis muscle contraction, improved pelvic floor relaxation and opening of the anal canal. Effective evacuation of the rectum was possible, whereas prior to apomorphine administra- 
Rest

PR

EAS

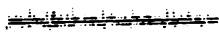

GM

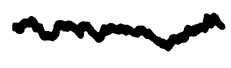

EO

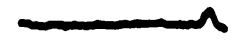

Squeeze
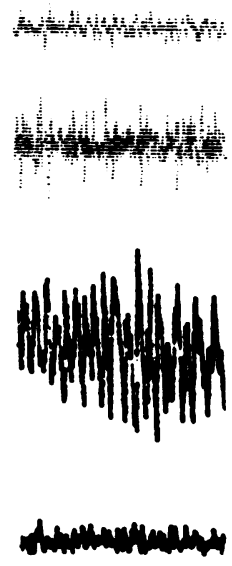

Push

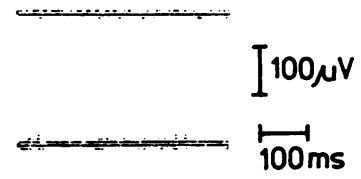

Fig 1 Control patient.

EMG recordings from

puborectalis (PR), external anal sphincter

(EAS), gluteus maximus

(GM) and external oblique (EO) muscles at

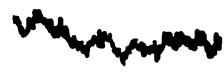

rest, during voluntary

sphincter contraction

(squeeze) and during

$\mathrm{I}^{25 \mu \mathrm{V}}$

simulated defaecation

straining (push). A

$\longmapsto \quad$ normal pattern of

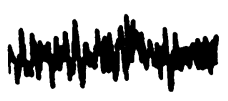

$100 \mathrm{~ms}$

sphincter muscle

inhibition is seen during

straining.

tion the patient had been unable to expel any of the rectal barium paste.

\section{Discussion}

Normal defaecation is a complex motor activity which is initiated voluntarily at some socially convenient time after the sensation of rectal distension by faecal material is perceived. The normal relaxation of the pelvic floor and sphincter muscles during straining and the brisk return of muscle activity at the end of defaecation has been well documented. ${ }^{11}$ Co-contrac-

Rest

PR

EAS

GM

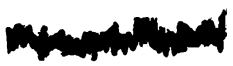

Squeeze
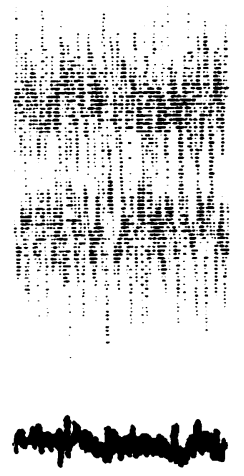

EO

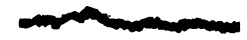

tion of glottic, diaphragmatic and abdominal wall muscles increases intra-abdominal pressure simultaneously with inhibition of activity in the pelvic floor and external anal sphincter muscles. Our results confirm that, in patients with anismus-type obstructive defaecation, this pattern of selective muscle contraction and inhibition is disturbed. Electromyographic activity in the puborectalis and external anal sphincter muscles which normally shows inhibition during attempted rectal balloon expulsion, was paradoxically augmented. Some patients demonstrated a tendency for excessive muscle recruitment during defaecation 


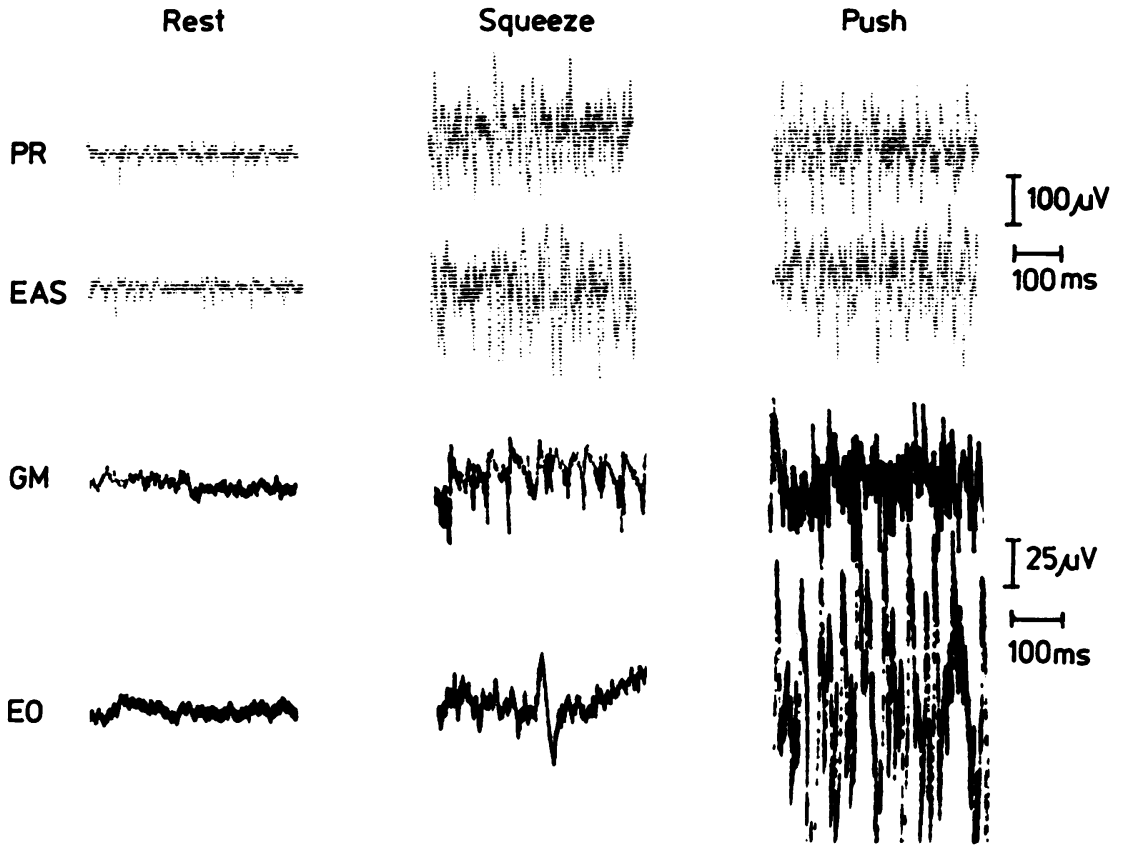

straining, with additional gluteal muscle activation. The pattern of muscle activation during other voluntary tasks such as coughing and voluntary anal sphincter squeezing appeared to be normal. The abnormalities observed during defaecation straining, consisting of paradoxical contraction of normally inhibited muscle groups, excessive muscle recruitment and the task-specific nature of the disturbance are characteristic features of focal dystonic syndromes affecting other parts of the body. Isolated involvement of single or adjacent muscle groups is typical of focal or segmental dystonias of adult onset. It is therefore logical to suggest that the anismus phenomenon represents a focal dystonia of pelvic and anal sphincter muscles.

Constipation, or the passage of infrequent stools, can result from slow intestinal transit or an impaired defaecation mechanism. Anismus and other conditions associated with tenesmus and difficulty evacuating the rectum have been collectively termed obstructive defaecation ${ }^{12}$ and include rectal intussusception and prolapse, anterior rectal mucosal prolapse and the descending perineum syndrome. These appear to be manifestations of chronic straining; the aetiology remains controversial. True anismus may be the underlying mechanism in some cases. ${ }^{3}$ However, in contrast to the anismus syndrome, difficulty with evacuation in the other forms of obstructive defaecation is due to mechanical factors.

Constipation is a common symptom in patients with
Parkinson's disease. Autonomic dysfunction, physical inactivity, impaired straining due to hypokinesia of the abdominal musculature and medication such as anticholinergic agents may be contributing factors. Although prominent autonomic failure in Parkinson's disease is not common, Lewy bodies have been described in spinal cord intermediolateral columns, in autonomic ganglia ${ }^{13}$ and in the colonic myenteric plexus. ${ }^{14}$ Neuronal loss in these regions is seldom severe. In contrast to the findings in multisystem atrophy associated with autonomic failure, ${ }^{15}$ Parkinsonian patients do not have EMG evidence of denervation in sphincter muscles ${ }^{16}$ to indicate significant degeneration in Onuf's nucleus, the sacral spinal cord nucleus containing motor neurons supplying the striated sphincter muscles. ${ }^{17}$ Our findings suggest that abnormal motor control of the striated anal sphincter mechanism may be an important cause of constipation in Parkinson's disease. Paradoxical sphincter muscle contraction was seen in four patients with Parkinson's disease and altered bowel habits. Constipation was temporally related to the development of the generalised extrapyramidal motor disorder in each case; in addition, constipation was strikingly responsive to dopamine agonist medication in one patient. The electrophysiological abnormalities of inappropriate activation of the pelvic floor and external anal sphincter muscles with straining in each case, and gluteal recruitment with straining in two cases, seemed indistinguishable from the findings in patients with 
idiopathic anismus-type obstructive defaecation. By contrast, no paradoxical muscle contraction was seen in the Parkinsonian patients without constipation.

These findings show that a stereotyped abnormality of striated sphincter muscle control is present in patients with idiopathic obstructive defaecation and also in constipated patients with Parkinson's disease who have a generalised disorder of the extrapyramidal motor system. It is suggested that in both of these groups, there is an organically based disturbance of central nervous system integration of voluntary sphincter control and that the syndrome of obstructive anismus-type defaecation could be considered to be an adult onset focal dystonic condition. Finding paradoxical pelvic floor muscle contraction in cases of generalised torsion dystonia would provide additional support for this hypothesis. As all of the individually recognised focal dystonic conditions can be observed in different patients with generalised dystonia, ${ }^{418}$ anismus-type involvement of the muscles of defaecation in such cases would be strong evidence of a dystonic basis for idiopathic anismus.

In common with adult-onset focal dystonia, idiopathic anismus is usually a persistent condition and is typically unresponsive to treatment. Regular use of aperients and enemas or surgical division of the puborectalis muscle are often ineffective. ${ }^{19}$ It may be of value to approach the treatment of anismus by considering therapeutic measures which have proved useful in patients with other focal dystonic conditions. Biofeedback therapy has been used with benefit in some cases of spasmodic torticollis and writer's cramp $^{2021}$ and might be useful in restoring more normal motor integration of the pelvic floor and sphincter muscles. ${ }^{22}$ Temporary paralysis of the orbicularis oculi muscles by local injection of botulinum toxin is effective treatment for blepharospasm. ${ }^{23}$ Partial paralysis of the striated sphincter muscles using this technique may help to restore normal function in patients with anismus. A trial of botulinum toxin injection, which produces temporary muscle weakness lasting for two to three months, may be worthwhile in patients with severe and intractable symptoms in whom pelvic floor surgery or colostomy are being considered.

SEM was supported by the St Mark's Hospital Research Fund. PAK was supported by the Kate Stillman Research Fellowship.

\section{References}

1 Preston DM, Lennard-Jones JE. Anismus in chronic constipation. Dig Dis Sci 1985;30:413-8.

2 Kuijpers HC, Bleijenberg G. The spastic pelvic floor syndrome. Dis Colon Rectum 1985;28:669-72.

3 Snooks SJ, Nicholls RJ, Henry MM, Swash M. Electrophysiological and manometric assessment of the pelvic floor in the solitary rectal ulcer syndrome. Br J Surg 1985;72:131-3.

4 Lees AJ. Tics and Related Disorders. Edinburgh: Churchill Livingston 1985.

5 Katchen M, Duvoisin RC. Parkinsonism following dystonia in three patients. Movement Disorders 1986;1:151-7.

6 Le Witt PA, Burns RS, Newman RP. Dystonia in untreated Parkinsonism. Clin Neuropharmacol 1986;9:293-7.

7 Poewe WH, Lees AJ, Stern GM. Dystonia in Parkinson's disease: clinical and pharmacological features. Ann Neurol 1988;23: 73-8.

8 Rothwell JC, Obeso A, Marsden CD. Pathophysiology of dystonias. In: Desmedt JE, ed. Advances in Neurology vol 39. New York: Raven Press 1983;851-63.

9 Berardelli A, Rothwell JC, Day BL, Marsden CD. Pathophysiology of blepharospasm and oromandibular dystonia. Brain 1985; 108:593-608.

10 Stibe CMH, Lees AJ, Kempster PA, Stern GM. Subcutaneous apomorphine in parkinsonian on-off oscillations. Lancet 1988; i:403-6.

11 Floyd WF, Walls EW. Electromyography of the sphincter ani externus in man. J Physiol (Lond) 1953;122:599-609.

12 Bartolo D, Roe A. Obstructed defaecation. Br J Hosp Med 1986:228-36.

13 Den Hartog Jager WA, Bethlem J. Incidence and characteristics of Lewy bodies in idiopathic paralysis agitans (Parkinson's disease). J Neurol Neurosurg Psychiatry 1960;23:283-90.

14 Kupsky WJ, Grimes MM, Sweeting J, Bertch R, Cote LJ. Parkinson's disease and megacolon: concentric hyaline inclusions (Lewy bodies) in enteric ganglion cells. Neurology 1987;37:1253-5.

15 Kirby R, Fowler C, Gosling J, Bannister R. Urethro-vesical dysfunction in progressive autonomic failure with multisystem atrophy. J Neurol Neurosurg Psychiatry 1986;49:554-62.

16 Fitzmaurice H, Fowler CJ, Rickards D, Kirby RS, Quinn NP, Marsden CD, Milroy EJG, Turner-Warwick RT. Micturition disturbance in Parkinson's disease. Br J Urol 1985;57:652-6.

17 Onuf (Onufrowicz) B. On the arrangement and function of the cell groups in the sacral region of the spinal cord. Arch Neurol Psychopathol 1900;3:387-411.

18 Fahn S, Marsden CD, eds. Classification and investigation of dystonia. In: Marsden CD, Fahr S, eds. Movement Disorders 2. London: Butterworths Scientific, 1987:332-58.

19 Kamm MA, Hawley PR, Lennard-Jones JE. Lateral puborectalis division in the management of severe constipation. $\mathrm{Br} J$ Surg 1988 (in press).

20 Korein J, Brudny J. Intergrated EMG feedback in the management of spasmodic torticollis and focal dystonia: a prospective study of 80 patients. In: Yahr MD, ed. The Basal Ganglia. New York: Raven Press, 1976:385-424.

21 Bindman E, Tibbetts RW. Writer's cramp: a rational approach to treatment. Br J Psychiatry 1977;131:143-8.

22 van Baal JG, Leguit P, Brummelkamp WH. Relaxation biofeedback conditioning as treatment for the disturbed defaecation reflex. Dis Colon Rectum 1984;27:187-9.

23 Elston JS, Ross Russell RW. Effect of treatment with botulinum toxin on neurogenic blepharospasm. Br Med J 1985;290: 1857-9. 